\title{
MATERIALS MODIFICATIONS WITH CLUSTER BEAMS: BULK AND SURFACE MODIFICATIONS
}

\author{
A. DunLoP* \\ Laboratoire des Solides Irradiés, Commissariat á l'Energie Atomique/ \\ Ecole Polytechnique, 91128 Palaiseau, France
}

It is now well accepted that electronic excitation and ionization arising from the slowing down of swift heavy ions can lead to structural modifications in some metallic targets as it has been known for a long time in insulators. A rapid overview of some results obtained after $\mathrm{GeV}$ monoatomic heavy ion irradiations will be given. It will then be shown that new specific effects take place during irradiations with cluster ions. The projectiles used are energetic cluster beams: 10 to $40 \mathrm{MeV} \mathrm{Au}_{4}$ or $\mathrm{C}_{60}$ ions. The rates of linear energy deposition in electronic excitation are close for $\mathrm{GeV}$ monoatomic and for $10 \mathrm{MeV}$ cluster ions, but the cluster ions have characteristic velocities which are one order of magnitude smaller than those of monoatomic ions. This leads to a strong spatial localization of the deposited energy during the slowing down process. The density of deposited energy can then reach values as high as a few $100 \mathrm{eV} /$ atom. This very high density of energy deposited in the electronic system of the targets can lead to spectacular structural modifications: generation in the vicinity of the ion trajectories of isolated or agglomerated point defects, new crystalline phases, amorphized regions. . After an overview of such damage induced in bulk metals, semiconductors, and insulators, we will discuss surface damage, consisting in the formation of bumps, craters, "lava-flows" on the target surface.

PACS numbers: $61.16 .-\mathrm{d}, 61.80 .-\mathrm{x}$

\section{Introduction}

This paper summarizes lectures which were given in September 1998 at the International School and Symposium on Physics in Material Science in Jaszowiec (Poland). The objective of the lectures is to give a flavour of the great variety of effects which can be observed in all types of targets (metals, insulators, semiconductors) following a very strong level of excitation of their electronic system. The excitation is obtained during the slowing down of energetic particles: we will successively consider monoatomic heavy ions ( $\mathrm{O}$ to $\mathrm{U}$ ) in the $\mathrm{GeV}$ energy range and cluster ions $\left(\mathrm{C}_{60}, \mathrm{Au}_{4}\right)$ in the $10 \mathrm{MeV}$ energy range. After a rapid presentation of the slowing down processes, an overview of the main results obtained in the last decade with monoatomic ions will be given before presenting very recent

*e-mail: annie.dunlop@polytechnique.fr 
results obtained following cluster irradiations. The specificities of the clusters will be emphasized.

When an energetic projectile penetrates into a target, it loses its energy via two nearly independent processes: (i) elastic collisions with the nuclei (nuclear energy loss $\left.(\mathrm{d} E / \mathrm{d} x)_{\mathrm{n}}\right)$, which dominate the ion slowing down in the low energy range (i.e. in the stopping region); (ii) electronic excitation and ionization (electronic energy loss $\left.(\mathrm{d} E / \mathrm{d} x)_{\mathrm{e}}\right)$, which strongly overwhelm $(\mathrm{d} E / \mathrm{d} x)_{\mathrm{n}}$ in the high energy range (typically above $1 \mathrm{MeV} /$ nucleon). Up to the 1980's it was considered that electronic energy deposition could participate to damage creation in many insulators [1], but the effects observed in bulk metals were solely ascribed to elastic nuclear collisions. This widely held opinion was due to the fact that in metallic systems the numerous very mobile conduction electrons allow a fast spreading of the deposited energy and an efficient screening of the space charge created in the projectile wake, so that it seemed unreasonable to hope for damage creation or track formation in metallic targets following high levels of electronic energy deposition.

The development of swift heavy ion accelerators delivering a few $10 \mathrm{MeV} /$ nucleon $\mathrm{O}$ to $\mathrm{U}$ beams has allowed to work in a regime in which the following conditions were realized: $(\mathrm{d} E / \mathrm{d} x)_{\mathrm{e}} \approx 1$ to $80 \mathrm{keV} / \mathrm{nm},(\mathrm{d} E / \mathrm{d} x)_{\mathrm{e}} /(\mathrm{d} E / \mathrm{d} x)_{\mathrm{n}} \approx$ 2000 which are very favourable to study damage creation induced by high $(\mathrm{d} E / \mathrm{d} x)_{\mathrm{e}}$. It was thus very tempting to (i) continue the studies of damage creation in insulators and (ii) check if, in such extreme conditions it was not possible to induce some damage in metallic targets following high electronic energy deposition [2].

When present, the microstructural modifications resulting from electronic energy deposition will always be localized in the close vicinity of the projectile paths and will hereafter be named as "tracks". They will be in most cases directly evidenced by transmission electron microscopy observations.

\section{Irradiations with GeV monoatomic heavy ions}

Two recent review articles [2,3] give some of the most important results concerning damage creation in insulators and metals, so that only the main important points will be listed below, with an emphasis on metallic targets in which quite a few unexpected results were obtained.

\subsection{Damage creation in the bulk of the targets}

\subsubsection{Creation of amorphous "latent tracks" in compound materials}

Quite a large variety of experiments concern damage creation in insulators irradiated by $\mathrm{GeV}$ heavy ions. Very detailed results concern in particular two types of oxides: (i) $\alpha$-quartz in which latent tracks are formed very easily $[4,5]$ and yttrium iron garnet $\mathrm{Y}_{3} \mathrm{Fe}_{5} \mathrm{O}_{12}$ (or $\mathrm{YIG}$ ) which is less sensitive to electronic excitations $[6,7]$. It was shown in both cases that amorphous latent tracks were indeed generated along the path of the projectiles as soon as the linear rate of energy deposition in electronic processes $(\mathrm{d} E / \mathrm{d} x)_{\mathrm{e}}$ exceeds a threshold $(\mathrm{d} E / \mathrm{d} x)_{\mathrm{e}}^{\mathrm{t}}$ value $\left(\approx 1 \mathrm{keV} / \mathrm{nm}\right.$ in $\mathrm{SiO}_{2}$ quartz, $\approx 4 \mathrm{keV} / \mathrm{nm}$ in YIG). A cross-section for damage creation resulting from electronic excitation effects could be deduced from the Rutherford backscattering measurements and transmission electron microscopy 

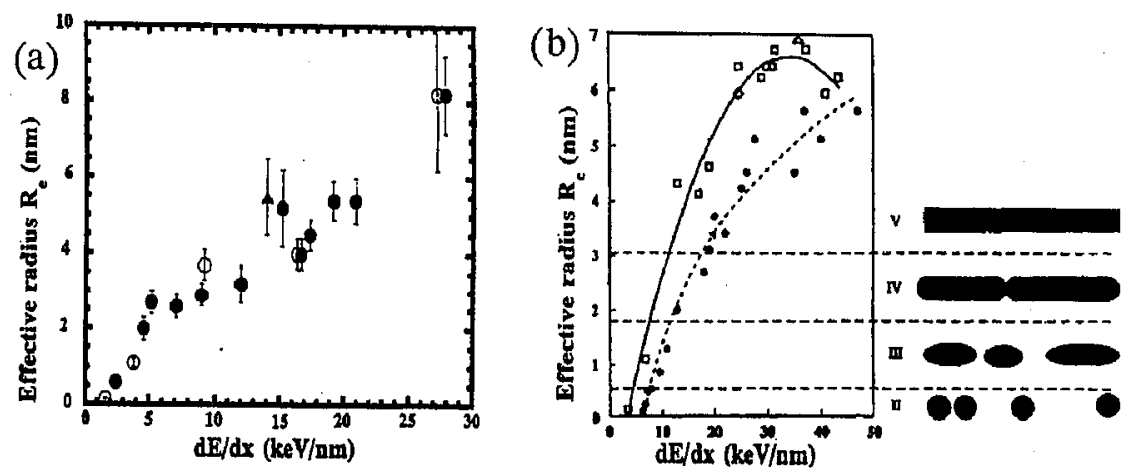

Fig. 1. Evolution of the effective track radius $R_{\mathrm{e}}$ as a function of the linear rate of energy deposition in electronic processes in $\mathrm{SiO}_{2}$ quartz ((a) from [5]) and YIG ((b) from [6]). Irradiations were performed on the GANIL accelerator in Caen (France) with a few $100 \mathrm{MeV}$ to a few GeV Ar to U ions. For YIG targets, the evolution of the damage morphology (from isolated damaged islands to a continuously damaged cylinder) is schematized on the right.

visualisation of the induced latent tracks. The evolution of the track radii with $(\mathrm{d} E / \mathrm{d} x)_{\mathrm{e}}$ was determined in both cases as reported in Fig. 1. The track morphology always evolves from isolated droplets to continuously damaged cylinders when $(\mathrm{d} E / \mathrm{d} x)_{\mathrm{e}}$ increases.

A very important point, the so-called "velocity effect" is shown in the lower part of Fig. 1. The continuous line joins points which are relative to low velocity projectiles $(\beta=v / c \leq 0.08)$ whereas the discontinuous line is relative to high velocity ions $(\beta \geq 0.12)$. For the same value of $(\mathrm{d} E / \mathrm{d} x)_{\mathrm{e}}$, the latent track radius increases when the irradiation is performed at a low velocity. This result is a direct consequence of the energy deposition process and will be discussed below.

Going now to metallic alloys, amorphous latent tracks were observed for the first time in intermetallic alloys, such as $\mathrm{NiZr}_{2}$ [8], $\mathrm{NiTi}$ [9] and $\mathrm{Ni}_{3} \mathrm{~B}$ [10]. The threshold for latent track creation is much higher than in insulators (now $\approx 40 \mathrm{keV} / \mathrm{nm}$ ), but here again an evolution from discontinuous droplets to continuous cylindrical damage is observed as $(\mathrm{d} E / \mathrm{d} x)_{\mathrm{e}}$ increases. These compounds were all known to be easily amorphisable by elastic collisions during irradiations with low energy ions or $\mathrm{MeV}$ electrons. At the opposite, no amorphisation resulting from electronic excitation processes could be evidenced after $\mathrm{GeV}$ ion irradiation, in high local symmetry compounds, such as $\mathrm{Zr}_{3} \mathrm{Al}$ and $\mathrm{Cu}_{3} \mathrm{Au}$, which are extremely difficult to amorphize by elastic collisions.

\subsection{2. "Latent track" creation in pure metals}

The study of the influence of high electronic energy deposition on damage processes in pure metals is not as easy as in metallic compounds, as there is certainly no chance to induce any amorphous tracks in metals by such methods. Most of the experiments consisted of low temperature $\mathrm{GeV}$ heavy ion irradiations of thin metallic ribbons, in order to avoid the stopping region of the projectiles and to stay in a regime in which the projectiles are mostly slowed down in electronic pro- 
cesses. The in situ measurement of the electrical resistivity of the samples during the irradiation allows the determination of the cross-section $\sigma_{\mathrm{d}}$ for damage creation during the bombardment. Nuclear collisions are always present: the cross-section $\sigma_{\mathrm{n}}$ for damage creation in these elastic processes can be calculated [11]. Figure 2 presents the evolution of the ratio $\xi=\sigma_{\mathrm{d}} / \sigma_{\mathrm{n}}$ (called the damage efficiency) of the measured to the calculated cross-sections as a function of $(\mathrm{d} E / \mathrm{d} x)_{\mathrm{e}}$. If electronic processes were inoperant in the targets, then the measured and calculated cross-sections should be equal: this is what is observed in a few targets, such as $\mathrm{Cu}, \mathrm{W}, \mathrm{Ag}$, in which damage results solely from elastic collisions [12].
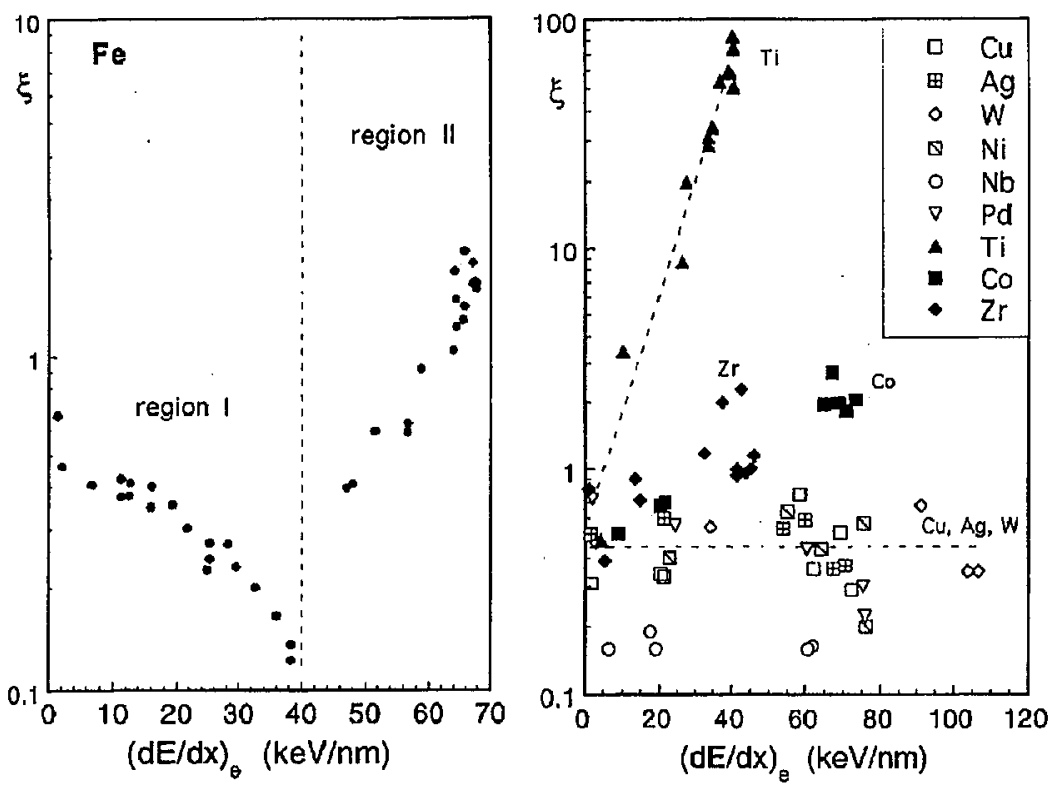

Fig. 2. Damage efficiency $\xi=\sigma_{\mathrm{d}} / \sigma_{\mathrm{n}}$ as a function of the linear rate of energy deposition in electronic processes $(\mathrm{d} E / \mathrm{d} x)_{\mathrm{e}}$ measured in metallic targets irradiated at $10 \mathrm{~K}$ with $\mathrm{O}$ to $\mathrm{U} \mathrm{GeV}$ ions (from [2]).

Iron has a particular behaviour [13]: two different regimes are clearly visible: in region I, the efficiency decreases monotonically as $(\mathrm{d} E / \mathrm{d} x)_{\mathrm{e}}$ increases, whereas in region II a spectacular increase in $\xi$ is observed. In region I part of the energy deposited in electronic excitation is converted into atomic motion leading to a partial recombination of the defects just created; in region II, a new mechanism of damage production appears: isolated point defects are generated [13], so that no contrast can be seen in an electron microscope.

Considering again Fig. 2, Ti, Co and $\mathrm{Zr}$ seem to be particularly easy to damage when submitted to electronic energy deposition. Electron microscopy observations were performed after low-temperature irradiations of titanium [14]. At low $(\mathrm{d} E / \mathrm{d} x)_{\mathrm{e}}(<26 \mathrm{keV} / \mathrm{nm})$, no damage is visible in the electron microscope. At higher $(\mathrm{d} E / \mathrm{d} x)_{e}$, after irradiation at a fluence of $\approx 10^{11} \mathrm{~cm}^{-2}$, "tracks" are observable. The damage is strongly localized along the ion wake, i.e. in the region 
in which electronic energy deposition is the most important. The damaged zones are not amorphous; they could consist of dislocation loops lying in the prismatic planes of the hcp structure of $\mathrm{Ti}$ [15]. In the same irradiation conditions, but at higher fluences $\left(\approx 10^{13} \mathrm{~cm}^{-2}\right)$, i.e. when the damaged zones spatially overlap, a phase change to another crystalline phase occurs. The sample evolves from the usual hcp $\alpha$-phase to the hexagonal $\omega$-phase [14], which is the high pressure phase of Ti. No damage has ever been visualized in the electron microscope in $\mathrm{GeV}$ ion irradiated zirconium [15] which indicates that only isolated defects or very small size defect clusters are induced by electronic energy deposition.

\subsubsection{Anisotropic growth in amorphous alloys}

A very spectacular effect of electronic energy deposition is the "anisotropic growth" phenomenon, which is observed in all amorphous targets. It consists of a macroscopic (up to $20 \%$ ) deformation of the irradiated samples, which shrink. along the ion beam direction and expand in the two perpendicular directions. This effect occurs (i) above a threshold in $(\mathrm{d} E / \mathrm{d} x)_{\mathrm{e}}(\approx 10 \mathrm{keV} / \mathrm{nm})$ and (ii) above an incubation fluence $\Phi^{\mathrm{t}}$. The higher $(\mathrm{d} E / \mathrm{d} x)_{e}$, the lower $\Phi^{t}$. The anisotropic growth has been studied in detail in $\mathrm{Pd}_{80} \mathrm{Si}_{20}[16,17]$ and $\mathrm{Fe}_{85} \mathrm{~B}_{15}$ [18] alloys and interpreted as follows $[19,20]$.

During the incubation period, damage is introduced along the projectile path, so that additional free volume is introduced in the amorphous structure. Some cylindrical regions of "disordered amorphous matter" are created. The only direct proof of the existence of such perturbed regions was obtained by chemical etching of some metallic glasses irradiated at low fluences. Etch cones were formed in the regions where the "disordered tracks" intercept the sample surface [21].

A radial shock wave propagates around the ion trajectory and induces rocking movements of pairs of atoms, which become oriented perpendicularly to the incident beam direction and result in the macroscopic deformations observed at higher fluences.

\subsection{Damage creation at surfaces and interfaces}

All the experiments reported above concern bulk damage, but high electronic excitations also play an important role in the damage processes at surfaces and interfaces. Enhancement of sputtering yields in metals by electronic excitations effects were reported under irradiation with $\mathrm{GeV}$ ions [22, 23]: for instance, the measured sputtering yield of a gold target irradiated with $\mathrm{GeV}$ uranium ions is found one order of magnitude higher than that awaited from elastic processes. High electronic excitations were also shown to be very efficient to induce atomic mixing in various multilayered targets [24-26].

\subsection{A few words about possible mechanisms by which defect generation could occur}

Quite a few models were proposed in the literature in order to account for damage creation induced by high levels of energy deposition in electronic processes. The problem of latent track creation in metallic targets seemed very difficult to explain, as (i) the large number of very mobile conduction electrons favors a rapid 
spreading of the deposited energy and a very efficient screening of the space charge generated in the vicinity of the ion path, (ii) collective processes have to be considered.

When an energetic ion enters a target: (i) a strong ionization of the target atoms located in the close neighbourhood of the ion path occurs and (ii) showers of excited $\delta$-electrons are ejected, so that a very high space charge density is created in a localized region. The nature of the resulting damage is directly related to the target nature and mainly depends on the lifetime of the excited states which governs the efficiency of the conversion of the energy into atomic motion. In metallic targets, the lifetime of the space charge is limited by the rapid screening by the conduction electrons, contrary to what happens in insulators.

The "thermal-spike" model, which was initially used to describe damage creation in insulators [27] was extended to metallic targets [28]. In this model, one mainly considers the conversion of the kinetic energy transmitted to $\delta$-electrons into lattice vibrations via electron-phonon coupling. A subsequent heating up of the lattice occurs. It can well account for damage generation in most insulators, for annealing processes as observed in iron, nickel [29].

The "ion-explosion spike" model was also initially proposed to account for damage creation in insulators and organic materials $[1,30]$. In insulators, the electrostatic potential energy resulting from the ionisation of the atoms is not screened. The recoil energy $E_{\mathbf{r}}$ due to the Coulomb repulsion can reach values up to a few $10 \mathrm{eV}$, which are sufficient to induce individual atomic displacements. In metallic targets, the efficient screening of the positive charges by the free conduction electrons makes such individual processes inoperant. However, a recent development has been proposed [31] in which one considers the continuous space charge generated along the ion path. The ionized matter is unstable; the lifetime of the space charge is limited by the response time of the conduction electrons to an electrostatic perturbation. The radial impulses received by all the atoms in the vicinity of the ion path correspond to $E_{\mathbf{r}}$ of 0.1 to a few eV [31]. Molecular dynamics simulations [32,33] have confirmed that structural modifications can indeed be induced in collective effects in which all the atoms located around the ion trajectory are repelled in a coherent way.

Other approaches are based (i) on the statistical deposition of the energy in electronic processes in order to account for some results in the "low velocity" regime [34], (ii) the role of target inner shell electron excitation which creates strong ionisation and leads to some damage creation [35], (iii) exciton interaction [36], (iv) the shock-wave model [37], (v) the core plasma model [38], (vi) a modified lattice potential [39].

Before concluding this paragraph, one should point out a very important point: the linear rate of energy deposition in electronic processes $(\mathrm{d} E / \mathrm{d} x)_{\mathrm{e}}$ is not the sole parameter allowing a satisfactory description of the damage processes in all types of targets. A clear experimental evidence is the "velocity effect" described above in YIG targets. Moreover, this is also obvious from the theoretical approaches:

(i) The velocities, and thus the ranges of the ejected $\delta$-electrons increase with the velocity of the projectiles. For similar $(\mathrm{d} E / \mathrm{d} x)_{e}$, i.e. considering monoatomic 
ions on both sides of the Bragg peak, the slower projectile will correspond to a much higher localisation of the deposited energy [40]. This increase in the density of deposited energy will induce stronger lattice damage.

(ii) The same conclusions are obtained from the Coulomb explosion approach in which it was shown [31] that damage creation is favoured when using high atomic number and low velocity projectiles.

These are the main points which initiated the more recent studies that will be described below. In order to increase the density of deposited energy in electronic processes and to search for spectacular structural modifications, very heavy clusters (mass $\approx 700$ ) of moderate velocities were used as projectiles.

\section{Irradiations with a few $10 \mathrm{MeV}$ heavy cluster ions}

The cluster projectiles used in the following experiments are mainly $\mathrm{C}_{60}$ and $\mathrm{Au}_{4}$ ions accelerated to 10 to $40 \mathrm{MeV}$ by the tandem accelerator, IPN/Orsay, France [41]. When such energetic clusters hit the target surface, they break into several fragments. These fragments stay in close proximity at the beginning of their path in the target and lose electrons. A spatial separation of the cluster constituents will occur due to:

(i) The Coulomb repulsion between the charged fragments. There is a screening by the target electrons. This effect depends on the energy of the projectile.

(ii) Multiple scattering due to the elastic collision processes: this effect increases as the projectile velocity decreases.

The objective of the work described below is to observe the evolution of the damage structure induced in a few targets as the projectiles slow down. The determination of the rate of energy deposition in electronic processes of cluster ions is still an open question, but the few available experimental results [42, 43] show that for carbon clusters, the energy loss per carbon is that of an individual carbon of the same velocity within experimental uncertainties, so that the energy loss of $\mathrm{C}_{60}$ is estimated as the sum of the energy loss of 60 individual carbon atoms. The same additive rule is used to calculate the linear rate of energy deposition in elastic processes on the basis of the TRIM code [44] which does not take into account additional effects that occur in connection with the penetration of molecules. A typical value of $(\mathrm{d} E / \mathrm{d} x)_{\mathrm{e}}$ for $20 \mathrm{MeV} \mathrm{C}_{60}$ ions slowing down in $\mathrm{Fe}$, Si or YIG is of $50 \mathrm{keV} / \mathrm{nm}$, i.e. slightly higher than the maximum value that one can reach using monoatomic projectiles (uranium at the Bragg peak at $\approx 1 \mathrm{GeV}$ ). The specificity of the fullerenes at a few $10 \mathrm{MeV}$ energies is that their velocities are one order of magnitude smaller than those of $\mathrm{GeV}$ heavy ions: $\beta=v / c \approx 0.01$ for $20 \mathrm{MeV} \mathrm{C}_{60}, \approx 0.1$ for $1 \mathrm{GeV} \mathrm{U}$, so that the maximum radial range of the ejected $\delta$-electrons is respectively of the order of a few interatomic distances and some $1000 \mathrm{~nm}$. This leads in the case of cluster irradiations to huge deposited energy densities of the order of $10 \mathrm{eV} / \AA^{3}$ [45]. The relaxation of such a localized high excitation leads to very spectacular structural modifications. A few examples detailed below in various types of targets (i) illustrate the strong damage which can be created at the beginning of the slowing down of the clusters when the fragments keep a good spatial correlation and (ii) show the direct observation of the consequences of the decorrelation of the fragments on the resulting damage. 


\subsection{Damage creation in the bulk of the targets}

\subsubsection{Results in some metallic crystalline targets}

The first observation of energetic heavy cluster damage was performed in titanium and zirconium targets [45]. Figure 3 presents comparative electron micrographs of titanium irradiated at $300 \mathrm{~K}$ with $850 \mathrm{MeV} \mathrm{Pb}$ ions and with $18 \mathrm{MeV}$ $\mathrm{C}_{60}$ ions. Both types of projectiles correspond to similar $(\mathrm{d} E / \mathrm{d} x)_{\mathrm{e}} \approx 40 \mathrm{keV} / \mathrm{nm}$, but $\mathrm{Pb}$ induces discontinuous tracks of about $5 \mathrm{~nm}$ diameter, whereas $\mathrm{C}_{60}$ creates continuously damaged cylindrical regions of about $20 \mathrm{~nm}$ diameter, which confirms that a strong localisation of the deposited energy induces a large extension of the damaged regions. Moreover, it has to be noted that the constant track diameter which is observed on a travelled length of about $100 \mathrm{~nm}$ on the lower right micrograph in Fig. 3 (thickness of the observed region of the irradiated target) indicates
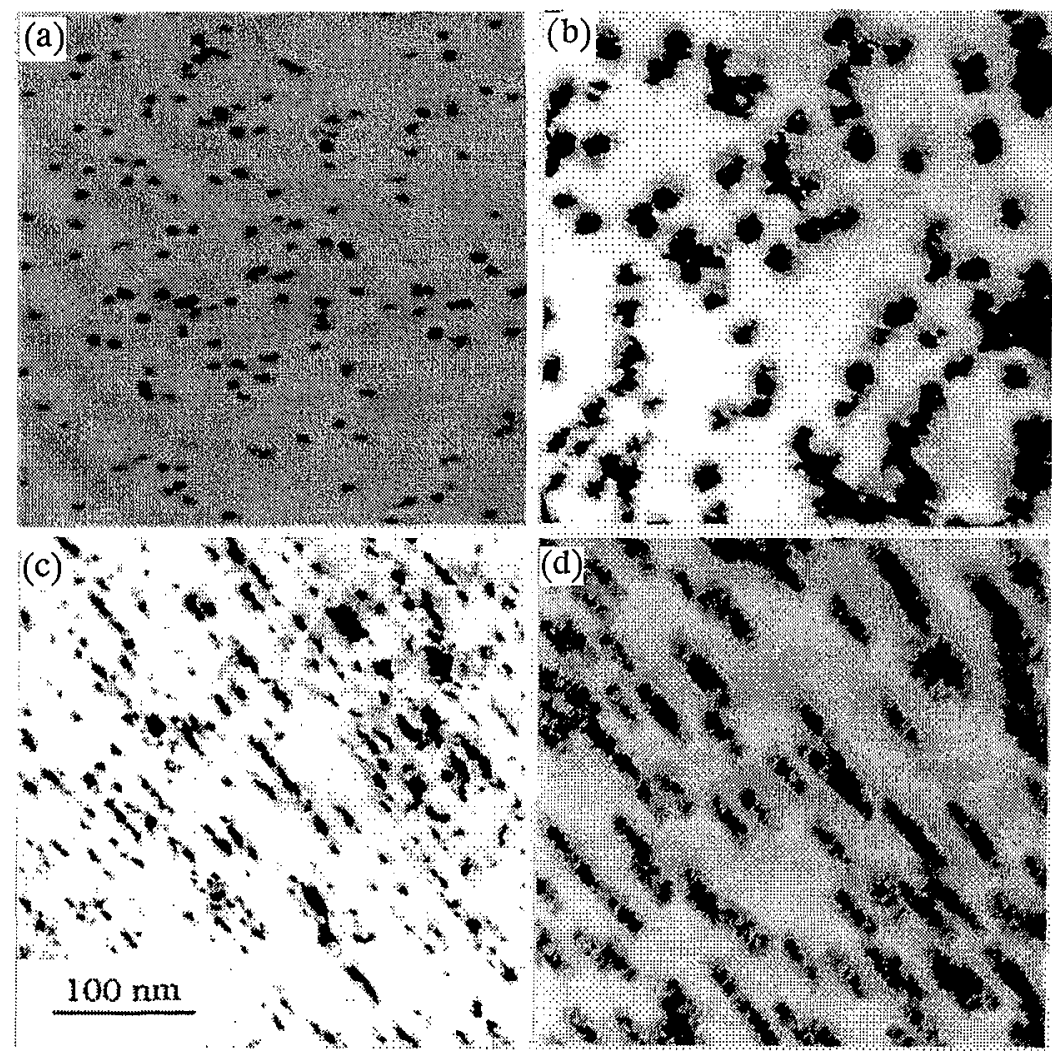

Fig. 3. Bright field electron micrographs of titanium irradiated at $300 \mathrm{~K}$ with $850 \mathrm{MeV}$ $\mathrm{Pb}$ ions (left side) and with $18 \mathrm{MeV} \mathrm{C}_{60}$ ions (right side). In the top micrographs, the electron beam direction is parallel to the ion beam. In the lower part, the samples were tilted by $\approx 30^{\circ}$ in the microscope in order to visualize the evolution of the damaged regions as the projectiles enter deeper into the targets (from [45]). 

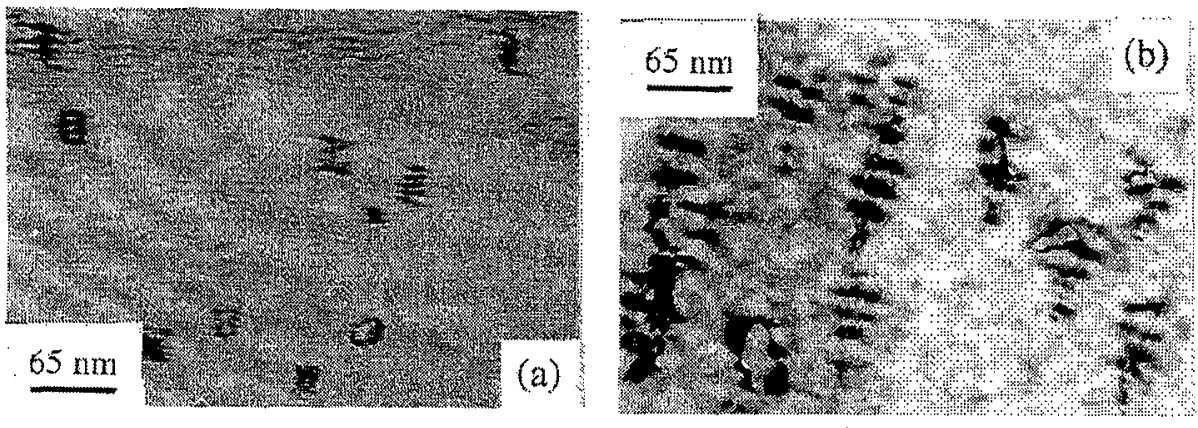

Fig. 4. Bright field electron micrographs of iron irradiated at $300 \mathrm{~K}$ with 20 (a) and 40 (b) $\mathrm{MeV} \mathrm{C}_{60}$ ions. The samples are tilted by $\approx 40^{\circ}$ in the electron microscope. Dislocation lines going through the sample thickness from one surface to the other one are visible (from [46]).

that the projectile fragments keep a good spatial correlation for a long distance before scattering significantly modifies the damage morphology. As observed after monoatomic ion irradiation, after fullerene irradiation the tracks consist of highly defective crystalline regions associated with dislocation loops located in the prismatic planes of the hexagonal structure of titanium.

Very recent experiments [46] also allowed the visualisation in an electron microscope of "latent tracks" in iron after irradiation at $300 \mathrm{~K}$ with 20 to $40 \mathrm{MeV}$ $\mathrm{C}_{60}$ ions: dislocation lines are observed in the vicinity of the projectile path, strain fields are confined in cylinders of 20 to $40 \mathrm{~nm}$ diameters (Fig. 4).

\subsubsection{Results in some insulators and semiconductors}

The use of insulating targets which are more sensitive than metals to electronic energy deposition, allowed the observation of the track shape evolution during the slowing down of fullerene ions and the observation of the separation of some tracks in various branches, which is a direct visualisation of the dissociation of the $\mathrm{C}_{60}$ molecule inside the target. After irradiation at $300 \mathrm{~K}$ with 10 to $40 \mathrm{MeV}$ $\mathrm{C}_{60}$ ions, large size amorphous tracks are generated in YIG [47]. These tracks keep a constant diameter for penetration depths $L \approx 100 \mathrm{~nm}$, which correspond to the correlated slowing down of the cluster fragments. Beyond these penetration depths, an evolution of the track shape is observed: gradual decrease in the diameter, separation in two or three branches (Fig. 5). It was shown that the evolution of the track diameter starts at a depth at which the trajectories of the various carbon atoms do not overlap sufficiently to allow to consider that there is a total correlation of all the constituents of the projectile: the variety and complexity of the observed track shapes result from the statistical nature of the energy loss and scattering processes.

Very interesting results were recently obtained in sapphire and in silicon. $\mathrm{Al}_{2} \mathrm{O}_{3}$ was one of the few insulators which were known to be extremely resistant to electronic energy deposition. No latent amorphous track could be generated during irradiations with $\mathrm{GeV}$ monoatomic heavy ions: only the creation of some disorder could be analysed using channeling Rutherford backscattering spectroscopy [48]. 


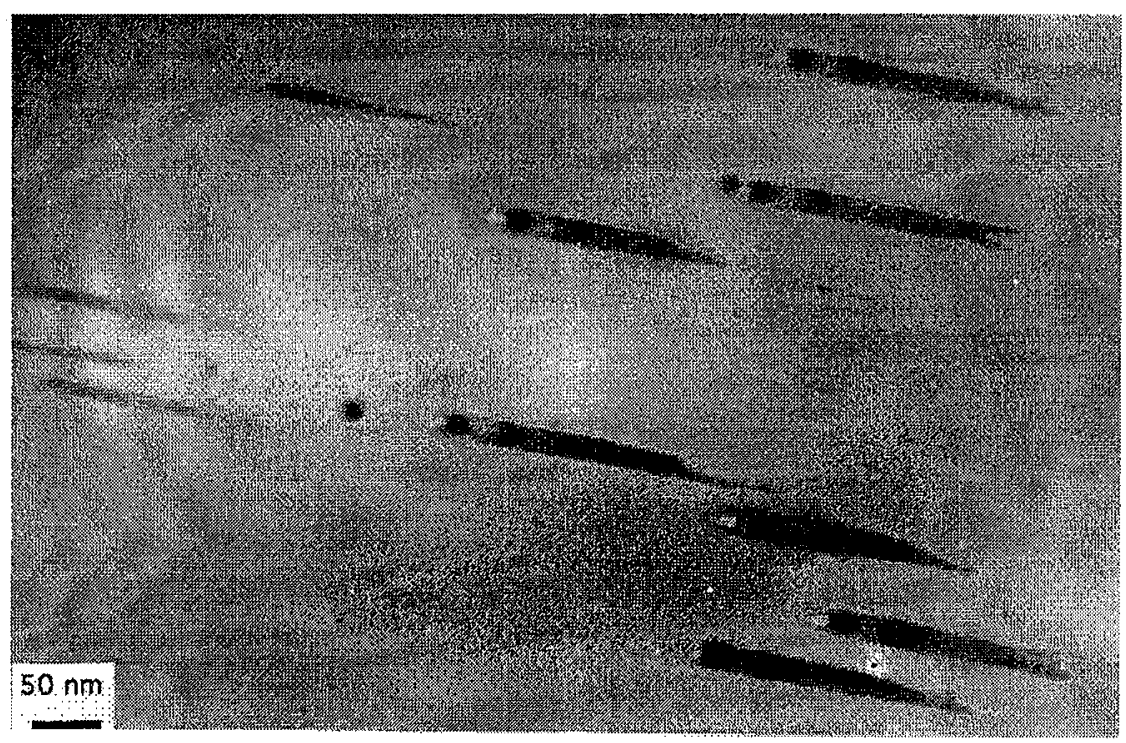

Fig. 5. Bright field electron micrograph of a YIG sample irradiated at grazing incidence with $40 \mathrm{MeV} \mathrm{C}_{60}^{3+}$ and $13.4 \mathrm{MeV} \mathrm{C}_{20}^{+}$ions, showing the track shape evolution as the fullerene ions penetrate deeper into the target (from [47]).
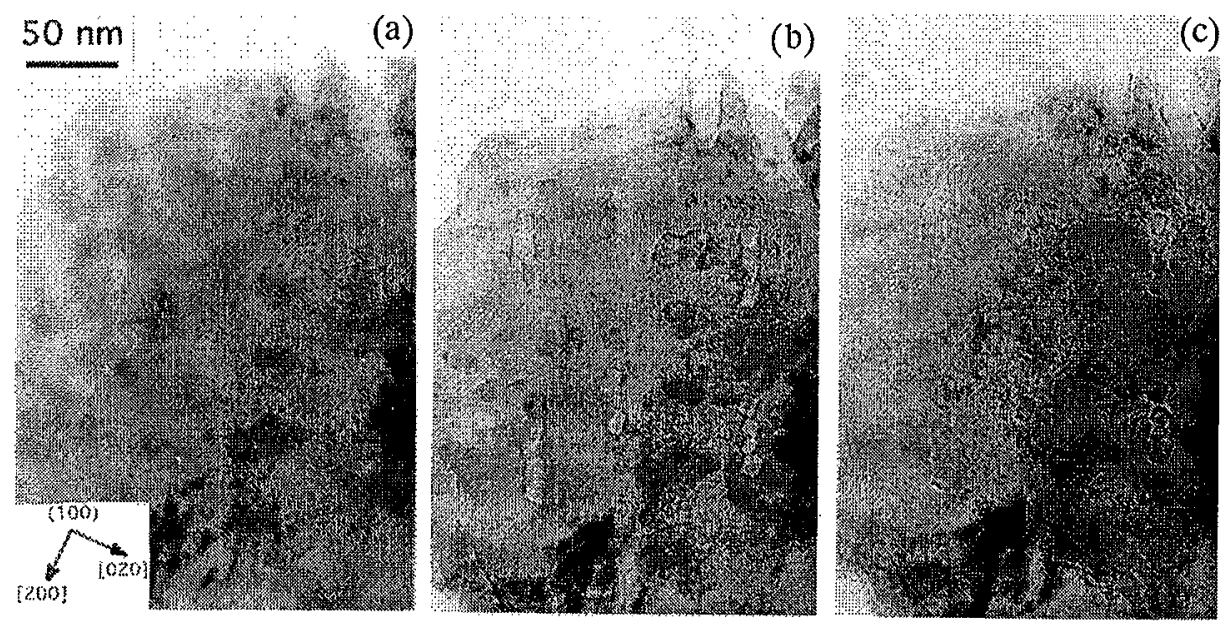

Fig. 6. Latent tracks induced in fluorite irradiated at $300 \mathrm{~K}$ and at normal incidence with $30 \mathrm{MeV} \mathrm{C}_{60}$ ions. The sample was tilted by $18^{\circ}$ in the electron microscope. The micrographs are taken from the $\langle 100\rangle$ direction in (a) bright field conditions and (b), (c) in phase contrast imaging conditions in order to better visualize the alignments of faceted metallic inclusions.

Under 10 to $30 \mathrm{MeV} \mathrm{C} 60$ irradiation, 8 to $13 \mathrm{~nm}$ diameter amorphous track are created in single crystals of $\alpha-\mathrm{Al}_{2} \mathrm{O}_{3}$ [49]. Similarly, amorphous track could be generated in monocrystalline silicon irradiated by energetic fullerene ions [50]: the 
tracks have typical diameters of $10 \mathrm{~nm}$. Their diameter stay constant on penetration depths of about $80 \mathrm{~nm}$ and then gradually decrease; the tracks very often end as aligned isolated droplets before disappearing at larger depths. The separation in various branches was not observed as in YIG.

We will finally quote that following high localised energy deposition under fullerene irradiation, it was possible to induce the formation of alignments of faceted metallic calcium inclusions (Fig. 6) along the projectile path in an ionic solid $\mathrm{CaF}_{2}$ [51].

\subsection{Damage creation at surfaces and interfaces}

Due to the high density of deposited energy, energetic cluster ions also induce very strong damage at the surface of the targets. We will detail below a few results concerning very high sputtering rates, crater formation, surface deformations, atomic mixing.

\subsubsection{Anisotropic growth of amorphous metallic alloys}

As recalled in Sec. 2.1.3, the anisotropic growth phenomenon occurring in all amorphous targets submitted to very high electronic excitations, was interpreted as resulting from the formation in a first step of "tracks of disordered amorphous matter" along the projectile path. Such disordered amorphous matter cannot be visualized in an electron microscope, but it was possible using the phase contrast technique, to observe in a transmission electron microscope the surface deformations which exist at the entrance and exit of the "tracks" in a thin amorphous target irradiated by $30 \mathrm{MeV} \mathrm{C} 60$ projectiles $[52,53]$. It was also possible to image the size of the impacts and surface deformations using transmission electron microscopy [52] and scanning tunneling microscopy [54] in amorphous alloys irradiated with $\mathrm{GeV} \mathrm{Pb}$ or $\mathrm{U}$ ions. The sizes of these surface features are found to be in perfect agreement with the diameters of the disordered cylinders that were earlier deduced from phenomenological approaches [55].

\subsubsection{Surface deformations and sputtering in various types of targets}

The formation of huge size craters at the impact of energetic cluster ions has been reported in all kinds of targets:

- observation of craters by atomic force microscopy in some inorganic materials such as mica and valine $[56,57]$.

- observation using standard electron microscopy methods and topographical contrast imaging conditions in an electron microscope of craters, "lava-flow" like surface deformations and onion like structures in a lamellar semi-conductor $\mathrm{MoS}_{2}$ irradiated with energetic fullerenes [58, 59].

- surface deformations consisting either in craters or bumpsat the emergence of latent tracks were observed in titanium, silicon [50], $\alpha-\mathrm{Al}_{2} \mathrm{O}_{3}$ [49], $\mathrm{Y}_{3} \mathrm{Fe}_{5} \mathrm{O}_{12}$ [60].

- very large sputtering rates could be measured under energetic cluster impacts [61]: it was shown in particular that large size clusters can be emitted from solids bombarded with high energy gold or fullerene cluster ions [62]. 


\subsubsection{Atomic mixing under energetic cluster bombardment}

The first detailed study of ion beam mixing effects under energetic cluster bombardment was performed in single crystals of magnesium oxide containing some sodium nanoprecipitates [63]. Electronic excitation induced mixing at the interfaces between the sodium precipitates and the $\mathrm{MgO}$ matrix induce a gradual decrease in the $\mathrm{Na}$ concentration and then a total destruction of the metallic precipitates.

\section{Conclusion}

All the results presented here show that if sufficient levels of energy deposition in electronic processes are reached, it is possible to induce permanent damage in most types of targets, i.e. in particular that these effects are no longer restricted to insulators. The only difference between metallic targets and insulators lies in the threshold above which damage creation becomes possible: $(\mathrm{d} E / \mathrm{d} x)_{\mathrm{e}}^{\mathrm{t}}$ of the order of a few $\mathrm{keV} / \mathrm{nm}$ in insulators and $40 \mathrm{keV} / \mathrm{nm}$ in most metals.

There is now a very clear evidence that the knowledge of $(\mathrm{d} E / \mathrm{d} x)_{\mathrm{e}}$ is not sufficient to characterise electronic energy deposition. The projectile velocity, which determines the density of deposited energy, is one of the main parameters governing damage creation, as was shown for example (i) in the results of irradiation of YIG with monoatomic projectiles on both sides of the Bragg peak and (ii) comparing at similar $(\mathrm{d} E / \mathrm{d} x)_{\mathrm{e}}$ rates, the morphologies of the damage resulting from irradiations with high velocity $\mathrm{Pb}$ or $\mathrm{U}$ ions to that obtained after $10 \mathrm{MeV}$ fullerene irradiation.

Other points of interest are that damage creation in the high electronic excitation regime involves collective effects and can lead to a very wide variety of damage structure in the "tracks" around the projectile path: isolated points defects (iron), dislocation loops (iron, titanium), evolution from a crystalline phase to another crystalline phase (titanium), "disordering" of amorphous targets, amorphisation $\left(\mathrm{Al}_{2} \mathrm{O}_{3}, \mathrm{SiO}_{2}, \mathrm{Y}_{3} \mathrm{Fe}_{5} \mathrm{O}_{12}, \mathrm{NiZr}_{2}, \mathrm{Si}\right)$, formation or dissolution of metallic inclusions in an insulating matrix $\left(\mathrm{CaF}_{2}, \mathrm{Na}\right.$ in $\left.\mathrm{MgO}\right)$. Very large surface deformations have also been observed.

Quite a number of theoreticians are now working on a precise description of the elementary mechanisms which govern the energy transfers from the electronic system to the lattice atoms and lead to the observed microstructural changes.

\section{References}

[1] R.L. Fleischer, P.B. Price, R.M. Walker, J. Appl. Phys. 36, 3645 (1965) and Nuclear Tracks in Solids, University of California Press, Berkeley 1975.

[2] A. Barbu, H. Dammak, A. Dunlop, D. Lesueur, Mater. Res. Soc. Bull. XX, no. 12, 29 (1995).

[3] J. Provost, Ch. Simon, M. Hervieu, D. Groult, V. Hardy, F. Studer, M. Toulemonde, Mater. Res. Soc. Bull. XX, no. 12, 22 (1995).

[4] J.P. Duraud, F. Jollet, Y. Langevin, E. Dooryhee, Nucl. Instrum. Methods Phys. Res. B 32, 248 (1988).

[5] A. Meftah, F. Brisard, J.M. Costantini, E. Dooryhee, M. Hage-Ali, M. Hervieu, J.P. Stoquert, F. Studer, M. Toulemonde, Phys. Rev. B 49, 12457 (1994). 
[6] A. Meftah, F. Brisard, J.M. Costantini, M. Hage-Ali, J.P. Stoquert, F. Studer, M. Toulemonde, Phys. Rev. B 48, 920 (1993).

[7] A. Meftah, J.M. Costantini, M. Djebara, N. Khalfaoui, J.P. Stoquert, F. Studer, M. Toulemonde, Nucl. Instrum. Methods Phys. Res. B 122, 470 (1997).

[8] A. Barbu, A. Dunlop, D. Lesueur, R.S. Averback, Europhys. Lett. 15, 37 (1991).

[9] A. Dunlop, D. Lesueur, A. Barbu, J. Nucl. Mater. 205, 426 (1993).

[10] A. Audouard, E. Balanzat, S. Bouffard, J.C. Jousset, A. Chamberod, A. Dunlop, D. Lesueur, G. Fuchs, R. Spohr, J. Vetter, L. Thomé, Phys. Rev. Lett. 65, 875 (1990).

[11] A. Dunlop, D. Lesueur, J. Dural, Nucl. Instrum. Methods Phys. Res. B 42, 182 (1989).

[12] A. Dunlop, D. Lesueur, Radiat. Eff. Defects Solids 126, 123 (1993).

[13] A. Dunlop, D. Lesueur, P. Legrand, H. Dammak, J. Dural, Nucl. Instrum. Methods Phys. Res. B 90, 330 (1994).

[14] H. Dammak, A. Barbu, A. Dunlop, D. Lesueur, N. Lorenzelli, Philos. Mag. Lett. 67, 253 (1993).

[15] H. Dammak, thesis, C.E.A. Report R-5668, 1994.

[16] S. Klaumünzer, G. Schumacher, S. Rentzsch, G. Vogl, L. Söldner, H. Bieger, Acta Metall. 30, 1493 (1982).

[17] S. Klaumünzer, Changlin Li, S. Löffler, M. Rammensee, G. Schumacher, H.Ch. Neitzert, Radiat. Eff. Defects Solids 108, 131 (1989).

[18] A. Audonard, E. Balanzat, G. Fuchs, J.C. Jousset, D. Lesueur, L. Thomé, Europhys. Lett. 3, 327 (1987); Nucl. Instrum. Methods Phys. Res. B 39, 18 (1989).

[19] A. Audouard, E. Balanzat, J.C. Jousset, D. Lesueur, L. Thomé, J. Phys. Condens. Matter 5, 995 (1993).

[20] Ming-Dong Hou, S. Klaumünzer, G. Schumacher, Phys. Rev. B 41, 1144 (1990).

[21] C. Trautman, R. Spohr, M. Toulemonde, Nucl. Instrum. Methods Phys. Res. B 83, 513 (1993).

[22] Yu.N. Cheblukov, D.G. Koshkarev, A.R. Peuto, I.V. Rudskoygh, J. Vetter, G.S.I. Scientific Report, Darmstadt, Germany 1989, p. 209.

[23] H.D. Mieskes, W. Assmann, M. Brodale, M. Dobler, H. Gluckler, P. Hartung, P. Stenzel, Nucl. Instrum. Methods Phys. Res. B 146, 162 (1998).

[24] J. Marfaing, W. Marine, B. Vidal, M. Toulemonde, M. Hage-Ali, J.P. Stoquert, Appl. Phys. Lett. 57, 1739 (1990).

[25] R. Leguay, A. Dunlop, F. Dunstetter, N. Lorenzelli, A. Braslau, F. Bridou, J. Corno, B. Pardo, J. Chevallier, C. Colliex, A. Menelle, J.L. Rouviere, L. Thome, Nucl. Instrum. Methods Phys. Res. B 122, 481 (1997).

[26] J. Pacaud, C. Jaouen, J. Grilhé, C. Dufour, P. Bauer, G. Marchal, J.C. Jousset, Radiat. Eff. Defects Solids 126, 369 (1993).

[27] L.T. Chadderton, H. Montagu-Pollok, Proc. R. Soc. Lond. A 274, 239 (1969).

[28] M. Toulemonde, C. Dufour, E. Paumier, Phys. Rev. B 46, 14362 (1992).

[29] A. Iwase, S. Sasaki, T. Iwata, Phys. Rev. Lett. 58, 2450 (1987).

[30] I.S. Bitensky, E.S. Parilis, Nucl. Instrum. Methods Phys. Res. B 21, 26 (1987).

[31] D. Lesueur, A. Dunlop, Radiat. Eff. Defects Solids 126, 163 (1993). 
[32] P. Legrand, J. Morillo, V. Pontikis, Radiat. Eff. Defects Solids 126, 151 (1993).

[33] P. Legrand, thesis, C.E.A. Report R-5639, 1993.

[34] E. Dartyge, P. Sigmund, Phys. Rev. B 32, 5429 (1985).

[35] T.A. Tombrello, Nucl. Instrum. Methods Phys. Res. B 2, 555 (1984).

[36] N. Itoh, Radiat. Eff. Defects Solids 110, 19 (1989).

[37] Y. Hayashiuchi, Y. Kitazoe, T. Sekiya, J. Nucl. Mater. 71, 181 (1977).

[38] R.H. Ritchie, C. Claussen, Nucl. Instr. Methods 198, 133 (1982).

[39] C.C. Watson, T.A. Tombrello, Radiat. Eff. Defects Solids 89, 263 (1985).

[40] S. Bouffard, Nucl. Instrum. Methods Phys. Res. B 107, 91 (1996).

[41] S. Della-Negra, A. Brunelle, Y. Le Beyec, J.M. Curaudeau, J.P. Mouffron, B. Waast, P. Hâkansson, B.U.R. Sundqvist, E.S. Parilis, Nucl. Instrum. Methods Phys. Res. B 74, 453 (1993).

[42] K. Baudin, A. Brunelle, M. Chabot, S. Della-Negra, J. Depauw, D. Gardes, P. Hakânsson, Y. Le Beyec, A. Billebaud, M. Fallavier, J. Remillieux, J.C. Poizat, J.P. Thomas, Nucl. Instrum. Methods Phys. Res. B 94, 341 (1994).

[43] Ch. Tomaschko, D. Brandl, R. Krügler, M. Schurr, H. Voit, Nucl. Instrum. Methods Phys. Res. B 103, 407 (1995).

[44] J.P. Biersack, L.G. Haggmark, Nucl. Instrum. Methods 174, 257 (1980); J.F. Ziegler, J.P. Biersack, U. Littmark, in: Stopping Power and Ranges of Ions in Matter, Vol. 1, Pergamon, New York 1985.

[45] H. Dammak, A. Dunlop, D. Lesueur, A. Brunelle, S. Della-Negra, Y. Le Beyec, Phys. Rev. Lett. 74, 1135 (1995).

[46] H. Dammak, A. Dunlop, Nucl. Instrum. Methods Phys. Res. B 146, 285 (1998).

[47] A. Dunlop, G. Jaskierowicz, J. Jensen, S. Della-Negra, Nucl. Instrum. Methods Phys. Res. B 132, 93 (1997).

[48] M. Toulemonde, E. Balanzat, S. Bouffard, J.J. Grob, M. Hage-Ali, J.P. Stoquert, Nucl. Instrum. Methods Phys. Res. B 46, 64 (1990).

[49] S.M.M. Ramos, N. Bonardi, B. Canut, S. Bouffard, S. Della-Negra, Nucl. Instrum. Methods Phys. Res. B 143, 319 (1998).

[50] A. Dunlop, G. Jaskierowicz, S. Della-Negra, Nucl. Instrum. Methods Phys. Res. $B$ 146, 302 (1998); B. Canut, N. Bonardi, S.M.M. Ramos, S. Della-Negra, Nucl. Instrum. Methods Phys. Res. B 146, 296 (1998).

[51] J. Jensen, A. Dunlop, S. Della-Negra, Nucl. Instrum. Methods Phys. Res. B 141, 753 (1998).

[52] A. Dunlop, G. Jaskierowicz, S. Della-Negra, C.R. Acad.Sci. Paris 325, série IIb, 397 (1997).

[53] A. Dunlop, J. Henry, G. Jaskierowicz, Nucl. Instrum. Methods Phys. Res. B 146, 222 (1998).

[54] A. Audouard, R. Mamy, M. Toulemonde, G. Szenes, L. Thomé, Europhys. Lett. 40, 527 (1997).

[55] A. Audouard, E. Balanzat, S. Bouffard, J.C. Jousset, A. Chamberod, A. Dunlop, D. Lesueur, G. Fuchs, R. Spohr, J. Vetter, L. Thome, Nucl. Instrum. Methods Phys. Res. B 59/60, 414 (1991). 
[56] D.D.N. Barlo Daya, A. Hallen, J. Eriksson, J. Kopniczky, R. Papaleo, C.T. Reimann, P. Hakânsson, B.U.R. Sundqvist, A. Brunelle, S. Della-Negra, Y. Le Beyec, Nucl. Instrum. Methods Phys. Res. B 106, 38 (1995).

[57] D.D.N. Barlo Daya, C.T. Reimann, P. Häkansson, B.U.R. Sundqvist, A. Brunelle, S. Della-Negra, Y. Le Beyec, Nucl. Instrum. Methods Phys. Res. B 124, 484 (1997).

[58] J. Henry, A. Dunlop, submitted for publication.

[59] J. Henry, A. Dunlop, S. Della-Negra, Nucl. Instrum. Methods Phys. Res, B 146, 405 (1998).

[60] J. Jensen, A. Dunlop, S. Della-Negra, H. Pascard, Nucl. Instrum. Methods Phys. Res. B 135, 295 (1998).

[61] K. Boussofiane-Baudin, A. Brunelle, P. Chaurand, S. Della-Negra, J. Depauw, P. Hakânsson, Y. Le Beyec, Nucl. Instrum. Methods Phys. Res. B 88, 61 (1994).

[62] K. Baudin, A. Brunelle, S. Della-Negra, D. Jacquet, P. Hakânsson, Y. Le Beyec, M. Pautrat, R.R. Pinho, Ch. Schoppmann, Nucl. Instrum. Methods Phys. Res. B 112, 59 (1996).

[63] M. Beranger, P. Thevenard, R. Brenier, B. Canut, S.M.M. Ramos, A. Brunelle, S. Della-Negra, Y. Le Beyec, E. Balanzat, T. Tombrello, Phys. Rev. B 53, 14773 (1996). 